\title{
Adverse effects of teenage pregnancy
}

\section{IMR Goonewardene ${ }^{1}$ and RPK Deeyagaha Waduge ${ }^{2}$}

(Index Words: Anaemia, pregnancy induced hypertension, preterm delivery, poverty)

\section{Abstract}

Rationale Recent studies have suggested that teenage pregnancies are not as hazardous as thought to be earlier.

Objective To compare the sociodemographic data, obstetric complications and attitudes towards family planning in teenagers and older women.

Design and Setting A prospective cohort study at the University Obstetrics Unit, Teaching Hospital, Galle.

Subjects and Method Sociodemographic data, details of antenatal care and family support, antenatal complications, gestation at delivery, mode of delivery, the proportion of unplanned pregnancies, and the possible effects of contraceptive counselling, in two groups of pregnant teenagers (13-16 years, $n=95$ and $17-19$ years, $n=250$ ) were compared with a control group of pregnant women (20-24 years, $n=275)$.

Results The teenagers were from lower socioeconomic strata and the younger teenagers were significantly less educated than the controls. Teenagers had a significantly higher risk of anaemia (Odds Ratio $(\mathrm{OR})=2.3,95 \% \mathrm{Cl}=$ 1.7-3.3, $\mathrm{p}<0.001)$. The younger teenagers had a significantly higher risk of gestational hypertension (OR $=4.8,95 \% \mathrm{Cl}=1.8-13.0, \mathrm{p}<0.001)$ and pre-eclampsia $(\mathrm{OR}=5.0,95 \% \mathrm{Cl}=1-27, \mathrm{p}=0.03)$. The older teenagers had a significantly higher risk of delivery before 34 weeks of gestation $(\mathrm{OR}=13.6,95 \% \mathrm{Cl}=1.8-287, \mathrm{p}=0.001)$. There were no significant differences in the mode of delivery. The younger teenagers had a much higher proportion (54\%) of unplanned pregnancies compared to the controls (16\%). A significantly higher proportion of younger teenagers (48\%) and older teenagers (25\%), if counselled, would have delayed their pregnancies compared to the controls (10\%).

Conclusion Teenage pregnancies, especially those below 17 years of age have a significantly higher risk of adverse outcomes. A large proportion of these pregnancies is unplanned and could be prevented by counselling.

\section{Introduction}

Teenage pregnancy, especially below 17 years of age, has been considered to have a higher risk than pregnancy in an adult, because of biological immaturity of the teenager. Adverse effects associated with teenage pregnancy include maternal anaemia $[1,2]$, pregnancy induced hypertension [1-3] , spontaneous miscarriage [4], low birthweight primarily due to preterm delivery and leading to a high perinatal and postneonatal morbidity and mortality [2, 5-7], high maternal mortality [8,9], the mother finding it difficult to cope with the pregnancy [10], and behavioural problems and poor cognitive abilities and achievements in the child later on [11]. There has been a worldwide increase in the rates of teenage pregnancy during the last three decades [12]. Teenage pregnancy is linked to poor education, poverty and social exclusion, and is a major worldwide public health problem [2, 5-7, 10-12]

${ }^{1}$ Professor and Head, and ${ }^{2}$ Registrar, Department of Obstetrics and Gynaecology, Faculty of Medicine, University of Ruhuna, Sri Lanka.

Correspondence: IMRG, e-mail: <malikg@eureka.lk> (Competing interests: none declared). Received 29 October 2004 and accepted 17 March 2005. 
Recently, several authors have suggested that young age itself does not carry a significantly higher risk of adverse pregnancy outcomes. However, they concede that the cumulative effects of the associated social and economic deprivation and exclusion on the health of these mothers and babies is a serious public health problem [1, 13].

There is concern that teenage pregnancy rates are increasing in Sri Lanka. In 2001, of the 165158 pregnant women who received antenatal care from a public health midwife, $7.8 \%$ were teenagers [9]. The proportion of teenage pregnancies was higher $(>11 \%)$ in the towns bordering the conflict affected areas [9]. In earlier studies from Colombo [14] and Anuradhapura [15], all the teenagers were grouped together although it is the younger teenager below 17 years who has been shown to have adverse effects in other studies [5-7]. The present study was conducted because no data were available from southern Sri Lanka.

\section{Subjects and methods}

All the nulliparous mothers aged less than 24 years at delivery presenting to the labour wards in the Teaching Hospital, Galle during a period of one year commencing 1.10. 2001 were interviewed and followed up until 6 weeks after delivery. Informed consent was obtained and a pretested questionnaire was used to obtain data.

Information on the maternal socioeconomic status, antenatal care received, the presence of family support, level of haemoglobin ( $\mathrm{Hb})$, obstetric complications, gestation at delivery, mode of delivery, birthweight of the baby, and attitudes towards family planning were collected when the subjects were recruited for the study and stored prospectively in a computer database. Anaemia was defined as $\mathrm{Hb}<11.0 \mathrm{~g} / \mathrm{dl}$. A diastolic blood pressure of $90 \mathrm{mmHg}$ or more recorded on two occasions at least 4 hours apart, occurring after 20 weeks gestation in a previously normotensive woman was defined as gestational hypertension, and in the presence of proteinuria it was defined as pre-eclampsia.

All the subjects had routine antenatal care either in a peripheral centre or at the Teaching Hospital Galle or both. The data was analyzed using Epi-info version-6 statistical package. Odds Ratios and 95\% Confidence intervals were calculated for the predictor variables-monthly income, education, utilisation of antenatal care, presence of good family support, each outcome variable, and the attitudes towards contraception, in the two study groups (young teenagers below 17 years of age and older teenagers 17-19 years of age ) using the 20-24 year age group as the controls. The pregnancy outcomes which were analysed included gestation at delivery, mode of delivery, birthweight of baby, and postnatal depression or psychosis in the mother.

\section{Results}

During the period of study there were 6500 deliveries and $345(5.3 \%)$ were teenagers, of whom 95 were young (13-16 years) and 250 were older (17-19 years). There were 275 controls (20-24 years) who were nulliparous. All consented to participate in the study.

Both teenage groups were significantly poorer and less educated $(\mathrm{p}<0.01)$ than the control group. Overall, the family support was good with more than $97 \%$ of the teenagers having parental support. Even in the control group only $20 \%$ presented for booking in the first trimester. In the older teenagers it was significantly less $(13 \%, \mathrm{p}=$ 0.02). More than $90 \%$ of women in each group attended a clinic at least five times and there were no significant differences between the groups (Table 1).

Table 1. Income, education, family support and antenatal care

\begin{tabular}{|c|c|c|c|}
\hline & $20-24$ years $(n=275)$ & $17-19$ years $(n=250)$ & $13-16$ years $(n=95)$ \\
\hline $\begin{array}{l}\text { Income }<\text { Rs. } 5000.00 \\
\text { per month }\end{array}$ & $53 \%$ & $\begin{aligned} 65 \% \quad \mathrm{OR} & =1.69 \\
95 \% \mathrm{CI} & =1.16-2.47 \\
\mathrm{p} & =0.002\end{aligned}$ & $\begin{aligned} 69 \% \quad \text { OR } & =1.99 \\
95 \% \text { CI } & =1.11-3.60 \\
p & =0.008\end{aligned}$ \\
\hline Only primary education & $2.5 \%$ & $\begin{aligned} 7.6 \% \quad \mathrm{OR} & =3.15 \\
95 \% \mathrm{CI} & =1.22-8.48 \\
\mathrm{p} & =0.006\end{aligned}$ & $\begin{aligned} 9.6 \% \quad \mathrm{OR} & =4 \\
95 \% \quad \mathrm{C} & =1.32-12.36 \\
\mathrm{p} & =0.004\end{aligned}$ \\
\hline Presence of good family support & $99 \%$ & $\begin{aligned} 97 \% \quad \text { OR } & =4.51 \\
95 \% \quad \mathrm{CI} & =0.87-31 \\
\mathrm{p} & =0.04\end{aligned}$ & $\begin{aligned} 98 \% \quad \text { OR } & =2.949 \\
95 \% \quad \mathrm{CI} & =0.29-30 \\
\mathrm{p} & =0.27\end{aligned}$ \\
\hline Booking in first trimester & $20 \%$ & $\begin{aligned} 13 \% \quad \text { OR } & =0.6 \\
95 \% \text { CI } & =0.36-1.02 \\
\mathrm{p} & =0.02\end{aligned}$ & $\begin{aligned} 19 \% \quad \mathrm{OR} & =0.92 \\
95 \% \mathrm{CI} & =0.45-1.88 \\
\mathrm{p} & =0.47\end{aligned}$ \\
\hline$\geq 5$ Visits & $96 \%$ & $\begin{aligned} 95 \% \quad \text { OR } & =1.2 \\
95 \% \quad \mathrm{CI} & =0.48-3.02 \\
\mathrm{p} & =0.41\end{aligned}$ & $\begin{aligned} 91 \% \quad \mathrm{OR} & =2.32 \\
95 \% \mathrm{CI} & =0.77-6.84 \\
\mathrm{p} & =0.08\end{aligned}$ \\
\hline
\end{tabular}

$95 \% \mathrm{CI}=95 \%$ confidence interval, $\mathrm{OR}=$ odds ratio 
Anaemia was detected in $30 \%$ of controls. A significantly higher proportion was anaemic in the teenage groups $(48-50 \%, \mathrm{p}<0.01)$. There was a significantly higher proportion of gestational hypertension $(12.6 \%, \mathrm{p}<0.001)$ and pre-eclampsia $(5.2 \%, \mathrm{p}=0.03)$ in younger teenagers compared to the controls ( $2.9 \%$ and $1.1 \%$ respectively) Younger teenagers may have a relatively higher rate of preterm delivery $(18.7 \%, \mathrm{p}=0.06)$ compared to the controls (11.4\%). Older teenagers had a significantly higher risk of very preterm delivery ( $<34$ weeks) compared to the controls $(\mathrm{OR}=13.6, \mathrm{p}=0.001)$ (Table 2).
There were no significant differences in either the mode of delivery or the delivery of a small for gestational age baby at term. There were no cases of puerperal depression or psychosis prior to discharge from hospital (Table 3).

There was a significantly greater proportion of unplanned pregnancies in young teenagers $(54 \%, \mathrm{p}<0.001)$ and older teenagers $(23 \%, \mathrm{p}=0.02)$ compared to the controls (16\%). Compared to the $9.5 \%$ in the control group, a significantly greater proportion of younger teenagers $(48 \%$, $\mathrm{p}=0.001)$ and older teenagers $(25 \%, \mathrm{p}<0.001)$ would have

Table 2. Obstetric complications

\begin{tabular}{|c|c|c|c|}
\hline $20-2$ & $=275)$ & $17-19$ years $(n=250)$ & $13-16$ years $(n=95)$ \\
\hline Anaemia & $30 \%$ & $\begin{aligned} 50.5 \% \quad \mathrm{OR} & =2.35 \\
95 \% \mathrm{CI} & =1.52-3.64 \\
\mathrm{p} & =0.001\end{aligned}$ & $\begin{aligned} 48 \% \quad \text { OR } & =2.13 \\
95 \% \mathrm{CI} & =1.09-4.15 \\
\mathrm{p} & =0.01\end{aligned}$ \\
\hline Gestational hypertension & $2.9 \%$ & $\begin{aligned} 2.8 \% \quad \mathrm{OR} & =0.96 \\
95 \% \mathrm{CI} & =0.31-2.9 \\
\mathrm{p} & =0.9\end{aligned}$ & $\begin{aligned} 12.6 \% \quad \mathrm{OR} & =4.83 \\
95 \% \mathrm{CI} & =1.76-13 \\
\mathrm{p} & <0.001\end{aligned}$ \\
\hline Pre-eclampsia & $1.1 \%$ & $\begin{aligned} 0.8 \% \quad \mathrm{OR} & =0.73 \\
95 \% \mathrm{CI} & =0.08-5.4 \\
\mathrm{p} & =0 . .54\end{aligned}$ & $\begin{aligned} 5.2 \% \quad \text { OR } & =5 \\
95 \% \mathrm{CI} & =1.01-27 \\
\mathrm{p} & =0.03\end{aligned}$ \\
\hline Delivery at < 37 weeks gestation & $11.4 \%$ & $\begin{aligned} 10.7 \% \quad \mathrm{OR} & =0.93 \\
95 \% \mathrm{CI} & =0.51-1.69 \\
\mathrm{p} & =0.45\end{aligned}$ & $\begin{aligned} 18.7 \% \text { OR } & =1.78 \\
95 \% \text { CI } & =0.88-3.60 \\
p & =0.06\end{aligned}$ \\
\hline Delivery at $<34$ weeks gestation & $1 *$ & $\begin{aligned} 12 *(4.9 \%) \mathrm{OR} & =13.61 \\
95 \% \mathrm{CI} & =1.80-287.2 \\
\mathrm{p} & =0.001\end{aligned}$ & $\begin{aligned} 1 * \mathrm{OR} & =2.91 \\
95 \% \mathrm{CI} & =0.00-109 \\
\mathrm{p} & =0.44\end{aligned}$ \\
\hline
\end{tabular}

* Number of cases, $95 \% \mathrm{CI}=95 \%$ confidence interval, $\mathrm{OR}=$ odds ratio

Table 3. Mode of delivery and birthweight at term

\begin{tabular}{|c|c|c|c|}
\hline & $20-24 \operatorname{years}(n=275)$ & $17-19 \operatorname{years}(n=250)$ & $13-16 \operatorname{years}(n=95)$ \\
\hline Normal vaginal delivery & $92.4 \%$ & $\begin{aligned} 94 \% \mathrm{OR} & =1.30 \\
95 \% \mathrm{CI} & =0.62-2.73 \\
\mathrm{p} & =0.45\end{aligned}$ & $\begin{aligned} 88.4 \% \text { OR } & =0.63 \\
95 \% \mathrm{CI} & =0.27-1.47 \\
\mathrm{p} & =0.23\end{aligned}$ \\
\hline Instrumental vaginal delivery & $2.2 \%$ & $\begin{aligned} 2.4 \% \text { OR } & =1.1 \\
95 \% \mathrm{CI} & =0.31-3.91 \\
\mathrm{p} & =0.86\end{aligned}$ & $\begin{aligned} 3.1 \% \mathrm{OR} & =1.46 \\
95 \% \mathrm{CI} & =0.28-6.74 \\
\mathrm{p} & =0.41\end{aligned}$ \\
\hline Caesarean delivery & $5.4 \%$ & $\begin{aligned} 3.6 \% \mathrm{OR} & =0.65 \\
95 \% \mathrm{CI} & =0.26-1.61 \\
\mathrm{p} & =0.3\end{aligned}$ & $\begin{aligned} 8.4 \% \text { OR } & =1.59 \\
95 \% \mathrm{CI} & =0.60-4.17 \\
\mathrm{p} & =0.3\end{aligned}$ \\
\hline Birthweight $<2.5 \mathrm{~kg}$ at term & $22.7 \%$ & $\begin{aligned} 24.8 \% \text { OR } & =1.13 \\
95 \% \mathrm{CI} & =0.71-1.799 \\
\mathrm{p} & =0.33\end{aligned}$ & $\begin{aligned} 20.3 \% \mathrm{OR} & =0.86 \\
5 \% \mathrm{CI} & =0.43-1.73 \\
\mathrm{p} & =0.39\end{aligned}$ \\
\hline
\end{tabular}

95\% CI $=95 \%$ Confidence Interval OR= odds ratio 
Table 4. Attitudes towards family planning

\begin{tabular}{|c|c|c|c|}
\hline & $20-24 \operatorname{years}(n=275)$ & $17-19 \operatorname{years}(n=250)$ & $13-16$ years $(n=95)$ \\
\hline Unplanned Pregnancies & $16 \%$ & $\begin{aligned} 23.2 \% \text { OR } & =1.59 \\
95 \% \mathrm{CI} & =1.00-2.52 \\
\mathrm{p} & =0.02\end{aligned}$ & $\begin{aligned} 54 \% \text { OR } & =6.1 \\
95 \% \mathrm{CI} & =3.50-10.61 \\
\mathrm{p} & <0.001\end{aligned}$ \\
\hline $\begin{array}{l}\text { Would have delayed the } \\
\text { pregnancy if counselled }\end{array}$ & $9.5 \%$ & $\begin{aligned} 25.3 \% \text { OR } & =3.23 \\
95 \% \mathrm{CI} & =1.91-5.48 \\
\mathrm{p} & <0.001\end{aligned}$ & $\begin{aligned} 48.4 \% \text { OR } & =9 \\
95 \% \mathrm{CI} & =4.8-16.7 \\
\mathrm{p} & =0.001\end{aligned}$ \\
\hline Thought of future contraception & $80.4 \%$ & $\begin{aligned} 75.2 \% \text { OR } & =0.74 \\
95 \% \mathrm{CI} & =0.48-1.15 \\
\mathrm{p} & =0.09\end{aligned}$ & $\begin{aligned} 51.5 \% \mathrm{OR} & =0.26 \\
95 \% \mathrm{CI} & =0.15-0.44 \\
\mathrm{p} & =0.001\end{aligned}$ \\
\hline
\end{tabular}

95\% CI $=95 \%$ confidence interval, $\mathrm{OR}=$ odds ratio

delayed the index pregnancy, if counselled. A significantly greater proportion of younger teenagers $(49 \%, p=0.01)$ had not thought of future contraception compared to the controls (20\%) (Table 4).

\section{Discussion}

The proportion of teenage pregnancies being terminated are as high as $40 \%$ in the USA [12], $60 \%$ in the UK [1], and 85\% in Italy [18]. Studies from these countries report the outcome of only the minority who continue the pregnancy. Extrapolation of these results and conclusions would not be appropriate in communities where physical maturation and overall nutrition is relatively poor, and termination of pregnancy is illegal.

In Sri Lanka almost all pregnant women, including teenagers, have good family support as reflected in the present study. Increased family support tends to increase the proportion continuing the pregnancy, and a better outcome for the mother and the baby [17]. In the present study, a significantly greater proportion of older teenagers presented for prenatal care late. However, the overall utilisation of antenatal care was good. Poor prenatal care contributes to the adverse outcome in teenage pregnancy $[2,3,5]$. However, large studies have clearly shown the adverse outcomes of teenage pregnancy in communities with good socioeconomic background and prenatal care [6], as well as in communities with socioeconomic deprivation and poor prenatal care where these confounding factors have been statistically adjusted for [5,7]. The present study reflects the good educational status in the country including the Galle district, but a significantly greater proportion of younger and older teenagers were less educated and had a lower monthly family income compared to the control group. Poor education has been strongly linked with teenage pregnancy $[12,18]$.

In the present study, about $50 \%$ of teenagers were anaemic and they had double the risk of developing anaemia during the antenatal period when compared to the controls. In studies previously carried out in Sri Lanka anaemia has not been identified nor its risks analysed
$[14,15]$. Nutritional anaemia mainly due to iron deficiency is the commonest prenatal complication seen in teenagers even in the UK, [1]. In the present study, young teenagers had a higher risk of developing gestational hypertension and pre-eclampsia and eclampsis compared to the controls. Earlier studies carried out in Sri Lanka failed to detect an increased risk of either pre-eclampsia or gestational hypertension in teenagers $[14,15]$. Large population based studies carried out earlier [3] as well as recent studies $[1,2,6]$ have shown an increased risk of pregnancy induced hypertension in teenagers.

Preterm delivery is the commonest complication associated with teenage pregnancy, and this leads to increased perinatal and neonatal deaths $[2,5,8]$. In Sri Lanka the management of pre-term deliveries remains a challenging problem. A preterm delivery rate of $37 \%$ among teenagers was reported earlier in Colombo, but no comparison was made with a control group [14]. In a study in the UK, teenagers did not have increased preterm delivery rates [1]. The present study showed that younger teenagers probably had a higher risk of preterm delivery, and very preterm delivery was a definite risk in the older teenagers.

As in our study, teenagers undergo labour and delivery well, and several studies have reported lower caesarean section rates in teenage mothers $[1,5,16]$. Fright and lack of co-operation in the second stage of labour may lead to an increased frequency of forceps delivery in teenagers [1]. In our study, teenage pregnancy had a significantly higher association with low birthweight, and this was due to preterm delivery and not fetal growth restriction. A study from Colombo reported low birthweight rates of $19 \%$ and $43 \%$ in teenagers, after correcting for period of gestation [14]. In a study from Anuradhapura, a significantly higher rate of low birthweight (34\% vs $23 \%$, $\mathrm{p}<0.001)$ was recorded in teenagers. Whether this was due to preterm delivery or fetal growth restriction was not analysed [15]. Several studies have failed to detect a higher risk of fetal growth restriction in teenagers [1,5-7].

In the our study, teenagers had a significantly higher proportion of unplanned pregnancies. Almost all the 
women with unplanned pregnancies admitted that they would have delayed the index pregnancy if they had been properly counselled and given appropriate contraceptive advice. In an earlier study in Galle it was found that $62 \%$ of teenage pregnancies were unplanned, and the main reason for not using contraceptives was ignorance or poor knowledge about contraception [19]. In the present study, almost half of the young teenagers had not thought of future contraception.

\section{Conclusion}

Teenage pregnancies, especially those below 17 years of age, are significantly associated with poverty, poor education, anaemia, pregnancy induced hypertension and preterm delivery. A large proportion of these pregnancies is unplanned and could be prevented by providing contraceptive counselling and services.

\section{References}

1. Konje JC, Palmer A, Watson A, Hay DM, Imrie A.. Early teenage pregnancies in Hull. British Journal of Obstetrics \& Gynecology 1992; 99: 969-73.

2. Verma V, Das KB. Teenage primigravidae: a comparative study. Indian Journal of Public Health 1997; 41: 52-5 .

3. Davies AM, Dunlop W. Hypertension in pregnancy. In: Barron SL, Thomson AM, eds. Obstetrical Epidemiology. London: Academic Press, 1983: 184-6.

4. Roman E, Stevenson AC. Spontaneous abortion. In: Barron SL, Thomson AM, eds. Obstetrical Epidemiology. London: Academic Press, 1983: 78-80.

5. Satin AJ, Leveno KJ, Sherman ML, Reedy NJ, Lowe TW, et al. Maternal youth and pregnancy outcomes. Middle school versus high school age groups compared with women beyond the teen years. American Journal of Obstetrics and Gynaecology 1994; 171: 184-7.

6. Olausson PO, Cnattingius S, Haglund B. Teenage pregnancies and risk of late fetal death and infant mortality. British Journal of Obstetrics and Gynaecology 1999; 106: 116-21.
7. Fraser AM, Brockert JE, Ward RH. Association of young maternal age with adverse reproductive outcomes. New England Journal of Medicine 1995; 332: 1113-7.

8. Kushwaha KP, Rai AK, Rathi AK, Singh YD, Serohi R. Pregnancies in adolescents: fetal neonatal and maternal outcome. Indian Paediatrics 1993; 30: 501-5.

9. Family Health Bureau, Ministry of Health Sri Lanka. Annual Report on Family Health Sri Lanka 2001: 5-22.

10. Myors K, Johnson M, Langdon R. Coping styles of pregnant adolescents. Public Health Nursing 2001; 18: 24-32.

11. Hofferth SL, Reid L. Early childbearing and children's achievement and behaviour over time . Perspectives of Ssexual and Reproductive Health 2002; 31: 41-9.

12. De Silva MO. Teenage sexual behaviour and pregnancy. Trends and determinants. In: Studd J, ed. Progress in Obstetrics and Gynaecology, 2003; 15: 123-33.

13. Jimenez MA, Martin AR, Garcia JR. Comparing the biological and psychosocial risks of pregnancy between groups of adolescents and adults. European Journal of Epidemiology 2000; 16: 527-32.

14. Attapattu JAF. Teenage pregnancy. Sri Lanka Journal of Obstetrics and Gynaecology 2000; 22: 11-20.

15. Weerasekera D. Adolescent pregnancies-is the outcome different? Ceylon Medical Journal 1997; 42:16-7.

16. D'Alfonso A, Carta G, Buttari F, Paolone G, Moscarini M. Pregnancy in adolescence; consequences and considerations. Minerva ginecologica 2000; 52: 351-7. [In Italian]

17. Rodriguez MA, Jimenez MA. Epidemiological assessment of the influence of socio-family factors in adolescent pregnancy. European Journal of Epidemiology 2001, 17: 653-9.

18. Westall J . Poor education linked with teenage pregnancies British Medical Journal 1997; 314: 537.

19. Gunarathne KA, Goonewardene M. Teenage pregnancy and contraception. Sri Lanka Journal of Obstetrics and Gynaecology 2001; 23: 15-9. 